\title{
Regional Patterns in the Otolith Chemistry of Juvenile Spotted Seatrout (Cynoscion nebulosus) Differ under Contrasting Hydrological Regimes
}

\author{
Chet F. Rakocinski ${ }^{1, *}$, Bruce H. Comyns ${ }^{1}$, Mark S. Peterson ${ }^{1}$ and Alan M. Shiller ${ }^{2}$ \\ ${ }^{I}$ Department of Coastal Sciences, The University of Southern Mississippi, 703 East Beach Drive, Ocean Springs, MS \\ 39564, USA; ${ }^{2}$ Department of Marine Science, The University of Southern Mississippi, 1020 Balch Boulevard, Stennis \\ Space Center, MS 39529, USA
}

\begin{abstract}
The value of using otolith chemistry to characterize recruitment in terms of natal source regions depends on how consistently spatio-temporal variation can be resolved. The objective of this study was to compare regional classification patterns in the otolith chemistry of juvenile Spotted Seatrout (Cynoscion nebulosus) between two years experiencing disparate hydrological regimes, and separated by a five year interlude. Spatial patterns in the whole-otolith chemistry of juveniles of this estuarine-dependent species were compared between years using five otolith elements and two stable isotopes. Consistent size-related trends in uptake and deposition were evidenced by parallel ontogenetic relationships for six otolith variables. Nine natal regions were discerned equally well in both years; and region accounted for similar overall amounts of variation in the seven otolith variables in both years. However, the otolith variables did not distinguish the nine regions in the same manner in both years, and natal regions varied in how similar they were in otolith chemistry between years. Consequently, between-year cross-classification accuracy varied widely among regions, and geographic distance per se was unimportant for explaining regional patterns in otolith chemistry. Salinity correlated significantly with regional patterns in otolith chemistry in 2001, but not at all in 2006 when conditions were much drier. Regional patterns in individual otolith variables reflected either a general trend based on hydrology, a regional-local effect whereby geographically closer regions exhibited similar otolith chemistry, or a location-specific effect for which there was either no correlation in otolith concentration among regions between years, or a significant but individualistic relationship. In addition to elucidating limitations of using otolith chemistry to identify natal source regions or for tracking fish movements, knowing more about how and why otolith chemistry varies could be used to address specific questions about early recruitment dynamics, or to aid in the development of more reliable instruments for discerning natal source contributions.
\end{abstract}

Keywords: Gulf of Mexico, Otolith Chemistry, Spatial Variation, Spotted Seatrout.

\section{INTRODUCTION}

The deposition of trace elements and isotopes into the crystalline lattice of otoliths is irreversible, and thus forms permanent records of environmental conditions [1,2]. Consequently otolith chemistry offers an insightful tool for discerning natal source contributions to stock structure [3-8] as long as chemical signatures of otoliths create natural records of conditions within source areas $[9,10]$. However, potential masking of regional patterns by different sources of variability needs to be better understood to reach the full potential of this approach. In addition to extrinsic changes in water chemistry [11-13] and physical conditions [2, 14], intrinsic sources of variation in otolith chemistry include mechanisms associated with physiology [15] and ontogenetic changes in diet [16] and metabolism [17, 18].

Resulting spatio-temporal variation in otolith chemistry also reflects numerous mediating factors [12]. Clear spatial patterns in otolith chemistry exist at spatial scales as fine as $10 \mathrm{~km}[2,19]$. However, the spatio-temporal scales on which

*Address correspondence to this author at the Department of Coastal Sciences, The University of Southern Mississippi, 703 East Beach Drive, Ocean Springs, Mississippi 39564, USA; Tel: +1 228-872-4284;

Fax: +1 228-872-4204; E-mail: chet.rakocinski@usm.edu spatial patterns are repeatable vary among studies [20]. Such variability often reflects the influence of changes in water chemistry as evidenced by a salinity gradient $[8,21]$. The efficacy of otolith chemistry for characterizing stock structure in terms of natal source contributions depends on the reliable discrimination of source regions [21-23], and also requires recognizing temporal limitations on those patterns $[2,7,15,20]$.

Inter-annual spatial patterns in otolith chemistry often reflect underlying differences in water chemistry [22-25] as subject to temporal hydrological effects [20, 26, 27]. Variable physical conditions, including salinity [11], water temperature [21], and oxidation reactions [28] regulate the availability of elements for otolith deposition. Consequently, the discrimination of natal source regions can be confounded in different years [29]. More studies need to examine how otolith chemical fingerprints vary relative to such influences on otolith variables.

Many otolith chemistry studies have been conducted within highly variable estuarine ecosystems. Using otolith chemistry to diagnose stock structure influenced by dynamic conditions confers both advantages and disadvantages. One advantage is that mixing of fluvial and oceanic water masses generates spatial heterogeneity in estuarine water chemistry, 
which facilitates the spatial resolution of natal source regions [21, 30]. Conversely, spatial patterns in otolith chemistry may vary at different temporal scales, spanning from seasonal to inter-annual to decadal $[1,2,18,29,31]$.

The estuarine-dependent sciaenid, Spotted Seatrout ( $C y$ noscion nebulosus) [32], is a heavily exploited game fish in Mississippi [33]. Because juvenile Spotted Seatrout reside in shallow shoreline and vegetated habitats for several months after settling [34], their otoliths retain discernable chemical signatures indicative of regional nursery conditions $[25,35$, 36]. Freshwater discharge from seven rivers facilitates the detection of natal source regions on a spatial scale of ca. 25 $\mathrm{km}$ along the $117 \mathrm{~km}$ coastline of Mississippi [36]. An equally fine spatial scale of resolution has been shown for Spotted Seatrout in Chesapeake Bay, and inter-annual differences in otolith chemistry have been shown on both the US Atlantic [37], and the Texas gulf coasts [25] for this species.

\section{Objectives}

The goal of this study was to compare regional patterns in the otolith chemistry of juvenile Spotted Seatrout between two years exemplifying disparate hydrological regimes. The following specific objectives were addressed: (1) were regional patterns the same between years?; (2) did regional patterns reflect geographic distances and/or differences in salinity?; (3) could fish be accurately cross-classified between years?; (4) how did the otolith variables correspond with between-year differences in regional patterns and crossclassification?

\section{MATERIALS AND METHODS}

\section{Field Collection}

Juvenile Spotted Seatrout were collected from 37 standard shoreline sites representing discrete nursery habitats widely dispersed throughout nine designated natal regions spanning from Grand Bay, Alabama to the Louisiana marshes, east of the Mississippi River [36]. The nine natal regions encompassed major physio-geographic features potentially contributing to Spotted Seatrout stock structure in Mississippi: Grand Bay (three sites), Horn Island (two sites), Biloxi Bay (five sites), Cat Island (three sites), St. Louis Bay (three sites), the Louisiana Marshes (three sites), the Chandeleur Islands (two sites), and the mouths of the Pascagoula (seven sites) and Pearl Rivers (nine sites). Specimens were aggregated at the regional level for analysis, and most of the same sites were sampled in both years. An effort was made to obtain a balanced data set in which every region was represented by between 22-24 specimens, thus some additional sites were required in 2006 to obtain adequate sample sizes. Only nine specimens were collected from the Pascagoula River in 2001 and 11 from Saint Louis Bay in 2006. Collections were made using a $15.2 \mathrm{~m}$ bag seine with $3.17 \mathrm{~mm}$ mesh. Specimens were returned to the laboratory on ice, frozen, and later thawed and measured prior to removing their otoliths.

\section{Otolith Chemistry}

Detailed otolith chemistry methods are presented in Comyns et al. 2008 [36]. Sagittal otoliths were removed from both sides of fish with acid-washed teflon-coated forceps, rinsed with ultrapure (Milli-Q) water, and stored in sterile 24-well cell culture clusters. In a Class 100 clean room equipped with a laminar flow bench, otoliths were individually placed into pre-weighed $(\mu \mathrm{g})$, acid-washed, microcentrifuge tubes using acid-washed teflon forceps. Centrifuge tubes were filled with $0.001 \mathrm{~N}$ re-distilled nitric acid using a metal-free polyetheylene pipette tip that had been triplerinsed with $0.1 \mathrm{~N}$ re-distilled nitric acid and triple-rinsed with Milli-Q water. Otoliths were washed with dilute acid to remove any residual contaminants (metal ions) from the otolith surfaces. After one to two min, acid was removed from the centrifuge tubes with a clean pipette tip, otoliths were triple-rinsed with Milli-Q water, and air-dried in the laminar flow bench for $24 \mathrm{~h}$. Centrifuge tubes containing cleaned otoliths were re-weighed to obtain otolith weights $(\mu \mathrm{g})$.

Otoliths from the left side were dissolved in a measured quantity of $0.1 \mathrm{~N}$ re-distilled nitric acid calculated to produce a final dissolved $\mathrm{Ca}$ concentration of $5 \mathrm{mM}$. Elemental analyses of whole-otolith solutions were performed using a ThermoFisher Element-2 sector field-inductively coupled plasma-mass spectrometer (ICP-MS) at the University of Southern Mississippi - Department of Marine Science. Calibration was achieved using external standards which were 5 $\mathrm{mM}$ in $\mathrm{Ca}$. Five trace elements ( $\mathrm{Ba}, \mathrm{Li}, \mathrm{Mg}, \mathrm{Mn}$ and $\mathrm{Sr}$ ) were measured at medium resolution on the ICP-MS. Samples were analyzed in random order to preclude confounding with any effects of instrument drift [3]. To minimize analytical error due to day-to-day and long-term changes in instrumental operating conditions, standards were matrix-matched to the dissolved otolith samples; that is, the samples and standards were all $5 \mathrm{mM}(+/-10 \%)$ in dissolved calcium. Additionally, a known quantity of In was added to all standards and samples as an internal standard to make preliminary adjustments for instrument drift and sensitivity changes. A high standard and a blank were run after every nine samples to correct for calibration drift and to check detection limits. In addition, a standard that was used for the analysis of the 2001 otoliths was preserved and re-run during the analysis of the 2006 otoliths. When calibrated using the standards for the 2006 analyses (and corrected for any evaporation using the known In spike), the old standard yielded results within $10 \%$ of its original concentrations. The molar concentrations of different elements were standardized to the number of calcium ions within otoliths and expressed as ratios to the molar concentration of $\mathrm{Ca}$.

Otoliths from the right side were analyzed for stable isotope ratios of $\delta^{13} \mathrm{C}$ and $\delta^{18} \mathrm{O}$. Otoliths were powdered with an agate mortar and pestle rinsed with Milli-Q water. Two mortars and pestles were alternately used and dried under a heat lamp. Powdered otoliths were transferred to acid-washed microcentrifuge tubes. Samples were pretreated by heating in vacuo at $75^{\circ} \mathrm{C}$ for $0.5 \mathrm{~h}$, and analyzed on a Micromass Optima isotope ratio mass spectrometer at the University of California, Davis, USA. Carbon dioxide from each sample was generated by acidification with phosphoric acid in a heated $\left(90^{\circ} \mathrm{C}\right)$ common acid bath. The resultant gas was purified and introduced into the mass spectrometer inlet system and compared against a standard reference gas of known isotopic value. Values of $\delta^{13} \mathrm{C}$ and $\delta^{18} \mathrm{O}$ were calculated against Vienna PeeDee Belemnite (VPDB). Mean precision 
was $(1$ sigma $) \pm 0.04$ per mille for $\delta^{13} \mathrm{C}$ and \pm 0.06 per mille for $\delta^{18} \mathrm{O}$.

\section{Data Analysis}

\section{Normalization and Ontogenetic Standardization}

Upon noting regionally heterogeneous variance using Levene's test in SPSS, the likely existence of regional differences in otolith weight as a covariate in 2001 and 2006 was tested with the sum of squares permutation based on Euclidian distances procedure $\left(\mathrm{Q}_{b}-E U D\right)$ [38], using MULTIV v. 2.4 [39]. The probability associated with a resultant $\mathrm{Q}_{b}$ value as conveyed by the pseudo F-ratio does not require equal variance among groups.

To facilitate elucidation of regional patterns, otolith variables were standardized relative to year and otolith weight. Trace elements (concentrations relative to $\mathrm{Ca}$ ) were $\log _{10}$ transformed to stabilize and normalize variances in regressions against $\log _{10}$ otolith weight. Stable isotope values were not transformed, as they are typically used directly for otolith studies [40-42]. One-sample Kolmogorov-Smirnov (K-S) tests for both stable isotopes failed to reject the null hypothesis of a normal distribution for all 18 year-by-region subsets $(P=0.097-0.997)$. Otolith variables exhibiting significant ontogenetic relationships were standardized using ANCOVA models which included Year as the main factor and $\log _{10}$ Otolith Weight as the covariate; with the preliminary inclusion of the Year $\times$ Otolith Weight interaction term to test the homogeneity of slopes assumption, which passed for all variables. If the main factor and covariate were significant, ANCOVA residuals for each year provided standardized values for further analysis. If the covariate was nonsignificant and the main factor significant, standardized $\mathrm{z}$ scores for each year from a one-way ANOVA provided standardized values. Where variance was heterogeneous, between-year significance was confirmed using the BrownForsythe and Welch methods in SPSS (version 18.0; www.01.ibm.com/software/analytics/spss). All otolith variables were standardized as z-scores prior to multivariate analyses of regional patterns.

\section{Multivariate Analyses}

Because variances in otolith variables were often heterogeneous among regions (i.e., significant Levene's tests within ANOVAs), overall significance of regional differences was determined with the sum of squares permutation based on Euclidian distances procedure $\left(\mathrm{Q}_{b}-E U D\right)$ [38], using MULTIV v. 2.4 [39].

Discriminant Function Analyses (DFAs) were conducted separately for each year (i.e., separate-year models), as well as for data pooled across both years (i.e., global model; excluding the Year factor; sensu Brown, 2006) [43] within SPSS (version 18.0; www.01.ibm.com/software/analytics/spss). DFAs included the seven otolith variables, and the lack of relatively small $\log$ determinants indicated that all regional groups could be retained in the DFAs [44]. The separate group covariance classification option in SPSS was chosen, which is comparable to performing a Quadratic DFA when the number of predictors (i.e., seven) does not exceed the number of groups minus one (i.e., eight) (IBM SPSS: http://www-01.ibm.com/ support/ docview.wss?uid
$=$ swg21479748). Priors for DFA classification were weighted proportionately to regional group sizes. $\mathrm{Q}_{b}-E U D$ tests [38] confirmed overall regional differences in the seven otolith variables.

\section{Multivariate Distance Patterns}

The Penrose Distance metric [45] represented regional differences across the higher dimensionality of the DFAs. Orthogonal DFA axes precluded the necessity for including co-variances; however, the Penrose Distance metric was modified to include a pooled weighted variance rather than assuming equal variances for yearly regional distributions. The inherent higher dimensionality of the Penrose distance matrix was depicted within 2-D space through Nonmetric Multidimensional Scaling (NMDS) using the Primer v6 software package (http://www.primer-e.com/).

For the global DFA model, the between-year interregional configuration was depicted within reduced 2-D NMDS space by standardizing raw Penrose distance values relative to total distances across the seven DFA axes for each region. Next, an interregional resemblance matrix was generated from the standardized inter-annual distance matrix. Groupings of regions based on inter-annual differences in global DFA space were identified using hierarchical cluster analysis of the resemblance matrix based on the group average linkage algorithm. The resulting interregional 2-D NMDS pattern was overlaid with a bubble plot that mirrored inter-annual distances within the global DFA space for each region.

NMDS ordinations also compared interregional configurations between the separate-year DFA models. In addition, NMDS ordinations represented interregional distances based on geographic proximity and salinity in each year. Hierarchical cluster analysis using the group average linkage method identified regional groups within the 2-D NMDS plots. To facilitate visual comparisons of regional configurations, each 2-D NMDS plot was oriented so that the Chandeleur Island region was situated within the upper central portion of the plot.

Correlations between interregional configurations of separate-year Penrose distance matrices in otolith chemistry, as well as between distance matrices representing geographic proximity and salinity were obtained by means of Mantel tests using the zt software tool [46]. The Mantel test uses a randomization procedure to ask whether distances among objects in one matrix are independent of distances for the same set of objects in another matrix, as represented by a different data set. Correlations involving interregional Euclidean distances in salinity tested whether salinity at the time of sampling correlated with regional variation in otolith chemistry in each year. Furthermore, a partial Mantel test examined how much the correlation between separate-year otolith chemistry distance matrices increased after controlling for the effect of geographic distance.

Cross-classification of specimens using classification functions from opposing years determined how consistently regional affinities of fish could be identified between years. Coefficients from Fisher's linear discriminant functions for the separate-year DFA models were used to cross-classify specimens. Predicted regions were assigned based on the 
highest score from among the DFA functions representing the nine regions.

Between-year regressions involving regional values for the otolith variables revealed how consistently they influenced regional patterns between years. In addition, a Principal Component Analysis (PCA) of the correlation matrix of the seven otolith variables as represented by the 18 year-byregion events revealed how the strengths and directions of associations varied among the otolith variables.

\section{RESULTS}

Widely disparate rainfall amounts likely influenced between-year differences in regional otolith chemistry patterns within the study area; mean monthly rainfall was almost twice as high across the coastal counties of Mississippi during the May through September period in $2001(18.5 \mathrm{~cm})$ than during the same period in $2006(10.2 \mathrm{~cm})$ (NOAA National Climatic Data Center) (Fig. 1). Corresponding regional differences in salinity were expressed over a narrower range during sampling in 2006 (from 12.5 to $32.3 \mathrm{psu}$ ) than in 2001 (from 5.2 to $32.2 \mathrm{psu}$ ).

(a)

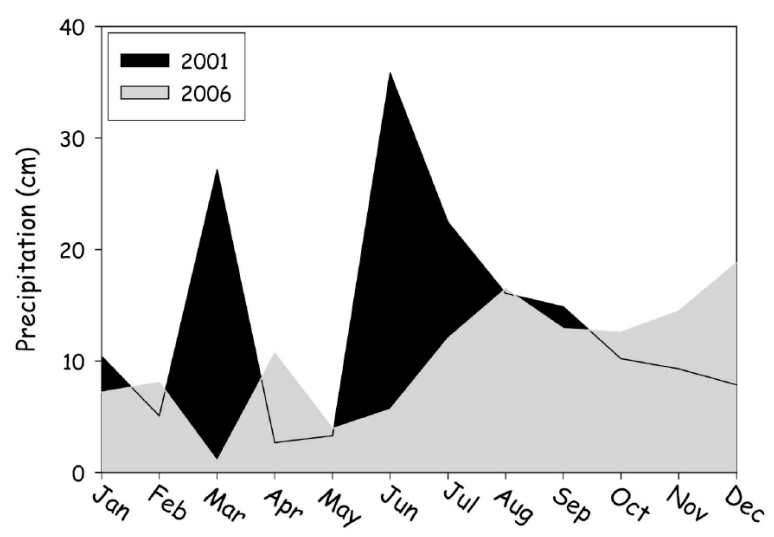

(b)

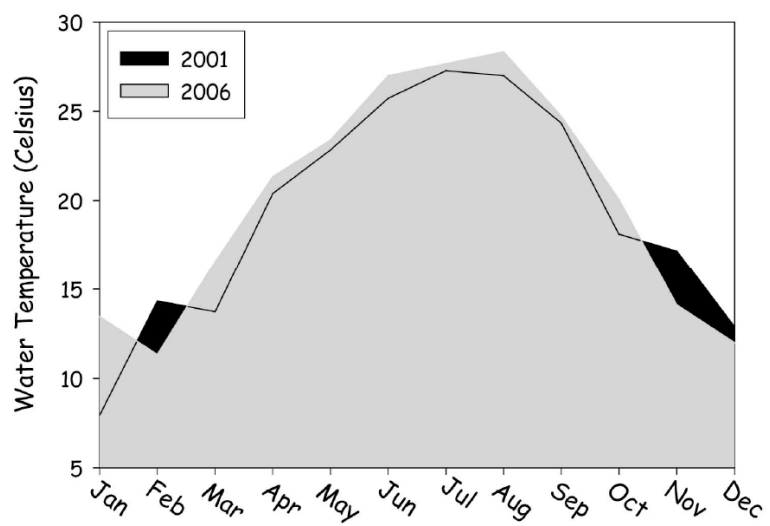

Fig. (1). (a) Monthly precipitation amounts for the Mississppi coast in 2001 and 2006. (b) monthly water temperature for the Mississippi coast. (NOAA National Climatic Data Center).

\section{Normalization and Ontogenetic Standardization}

The nine regions included otolith data for 197 juvenile fish in 2001 and 201 fish in 2006. Significant regional differences in otolith weight existed among regions in both $2001\left(Q_{b}-E U D\right.$ tests; pseudo $\left.F=2.90 ; \mathrm{P}<0.0001\right)$ and 2006 (pseudo $F=1.83 ; \mathrm{P}<0.0001$ ). Although regional differences in otolith weight in 2006 did not specifically match those in 2001 [36], the extent of regional variation in inferred fish size was comparable in both years.

For the otolith variables $\mathrm{Ba}, \mathrm{Li}, \mathrm{Mg}, \mathrm{Mn}, \delta{ }^{13} \mathrm{C}$, and $\delta^{18} \mathrm{O}$, levels depended on otolith weight as a covariate within ANCOVAs $(\mathrm{F}=4.93-51.90 ; \mathrm{P}=0.027-<0.001)$, for which the Year factor also was significant $(F=7.80$ $-148.00 ; \mathrm{P}=0.005-<0.001)$. The lack of any between-year differences in slopes relative to otolith weight implied that ontogenetic relationships were parallel for all six variables $\left(\right.$ Year $\times \log _{10}$ Otolith Weight $\mathrm{F}=0.01-3.64 ; \mathrm{P}=0.057$ $-0.911)$. For $\mathrm{Sr}$, the ontogenetic relationship was not significant $(\mathrm{F}=0.55 ; \mathrm{P}=0.459)$, although the Year factor was significant $(\mathrm{F}=4.13 ; \mathrm{P}=0.043)$. For five otolith variables exhibiting unequal variance between years $(F=4.78$ 238.52; $\mathrm{P}=0.029-<0.001)$, Browne-Forsythe and Welch tests confirmed significant between-year differences (test statistic $=4.11-141.02 ; \mathrm{P}=0.043-<0.001)$. Standardized residuals from these relationships were used for further analyses of regional patterns.

\section{Multivariate Analyses}

Otolith chemistry varied significantly among the nine regions in both 2001 and $2006\left(Q_{b}-E U D\right.$ tests; 2001 pseudo $F$ $=0.66 ; \mathrm{P}<0.0001 ; 2006$ pseudo $F=0.56 ; \mathrm{P}<0.0001)$. All seven otolith variables varied significantly among the nine regions in both years (ANOVA; 2001: $\mathrm{F}=14.64-484.01$; all $\mathrm{P}<0.001$; 2006: $\mathrm{F}=14.69-132.57$; all $\mathrm{P}<0.001)$. Thus, all seven otolith variables were deemed useful for regional DFA classifications.

Regional associations of the otolith variables differed between years, but $\delta^{13} \mathrm{C}$ and $\delta^{18} \mathrm{O}$ showed the strongest associations with the Region factor in both years (partial $\eta^{2}$ of 0.90 and 0.95 in 2001 vs. partial $\eta^{2}$ of 0.80 and 0.82 in 2006, respectively; i.e., where partial $\eta^{2}=\mathrm{SS}_{\text {effect }} / \mathrm{SS}_{\text {effect }}+\mathrm{SS}_{\text {error }}$ ). Of the trace elements, Li showed the strongest association with region in 2001 (i.e., partial $\eta^{2}=0.80$ ); whereas, Ba showed the strongest association with region in 2006 (i.e., partial $\eta^{2}$ $=0.80)$. Remarkably, an inter-annual correlation of 0.903 between regional partial $\eta^{2}$ values for the seven otolith variables $(\mathrm{P}<0.0025,1$-tail) demonstrated similar relative variances in the otolith variables in both years. However, regional patterns were not expressed in the same manner in both years.

Separate-year DFAs effectively distinguished regions in both 2001 and 2006 (Functions 1-7 together; Wilks $\Lambda=$ 0.001 ; $\mathrm{P}<0.001$ both years). The first four DFA axes accounted for $96.7 \%$ of the total variance in the seven otolith variables in 2006 (40.1\% for DF1, 32.8\% for DF2, $14.8 \%$ for DF3, and $9.0 \%$ for DF4). By contrast, the first four DFA axes similarly accounted for $98.8 \%$ of the total variance in 2001 (75.0\% for DF1, 15.4\% for DF2, 7.1\% for DF3, 1.3 for DF4), but DF1 was notably stronger in 2001 than in 2006.

Joint consideration of correlations and standardized coefficients revealed how otolith variables influenced the DFA axes differently in each year (Table 1). Influences of variables were more diffuse in 2006 than in 2001. In 2001, DF1 was primarily influenced by $\delta^{18} \mathrm{O}, \mathrm{DF} 2$ by $\mathrm{Mn}$ and $\delta^{13} \mathrm{C}$, and DF3 by Ba. By contrast in 2006, DF1 was primarily 
Table 1. Correlation coefficients (Corr) and standardized coefficients (SC) for the seven otolith chemistry variables within the Discriminant Function Analyses in 2001 and 2006. Bold values indicate correlations that are predominantly high for a particular otolith variable.

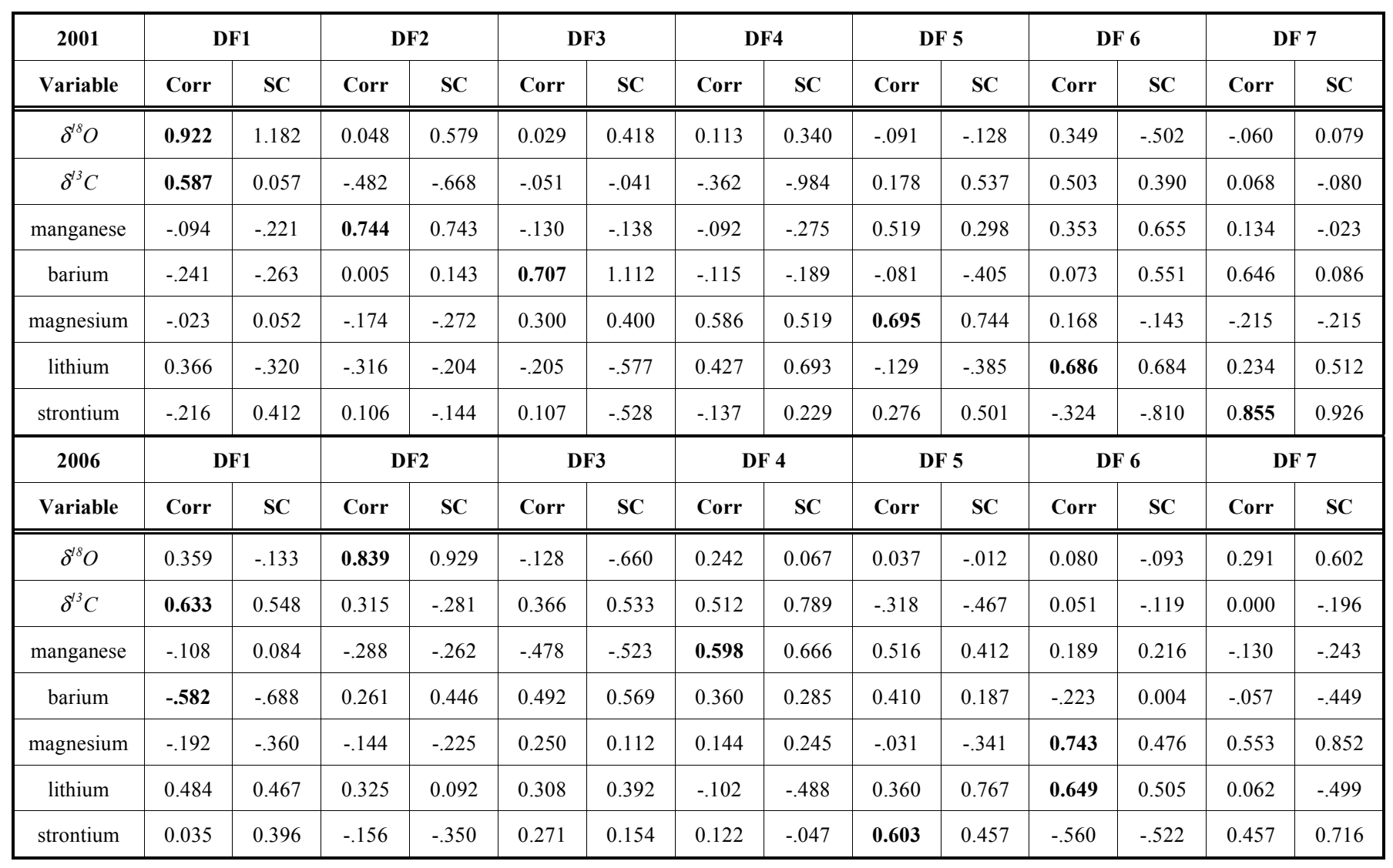

influenced by $\mathrm{Ba}, \delta^{13} \mathrm{C}$, and $\mathrm{Li}, \mathrm{DF} 2$ by $\delta^{18} \mathrm{O}$, and $\mathrm{DF} 3$ by $\mathrm{Ba}, \mathrm{Mn}$, and $\delta^{13} \mathrm{C}$. In $2001, \delta^{18} \mathrm{O}$ and $\delta^{13} \mathrm{C}$ correlated strongest with DF1, Mn with DF2, Ba with DF3, Mg with DF5, Li with DF6, and Sr with DF7; and in 2006, $\delta^{13} \mathrm{C}$ and Ba correlated strongest with DF1, $\delta^{18} \mathrm{O}$ with DF2, Mn with DF4, Sr with DF5, and Mg as well as Li with DF6.

Plots of scores for individual fish within the first two DFA dimensions together with regional centroids showed good separation of the nine regional groups in both years (Fig. 2). In 2001, the arrangement of regional groupings along DF1 clearly reflected the salinity gradient (Fig. 2a) [36]. Also, some effect of geographic proximity was apparent within the 2001 DFA plot. However, the 2006 regional configuration within the first two DFA dimensions did not match that of 2001 (Fig. 2b). In general, the regions were not as well separated within the 2006 DFA plot compared to the 2001 plot.

\section{Multivariate Distance Patterns}

Configurations of regions within 2-D NMDS plots derived from higher dimensional Penrose distances represented regional differences across the higher dimensionality of the DFAs (Figs. 2 and 3). In addition, regional configurations within 2-D NMDS plots of DFAs differed between years as well as within a NMDS plot portraying physical distances among regions. The NMDS plot of physical distances mirrored the geography, including distinct clusters of eastern and western regions, as well as with the Chandeleur Islands standing out as an isolated region (Fig. 3a). The Chandeleur Island region was similarly isolated within the NMDS plot based on 2001 otolith chemistry (Fig. 3b). However, regional groupings within the 2001 NMDS plot revealed the inferred salinity gradient better than geographic distance. Regions generally clustered closer together in the 2006 NMDS plot than in the 2001 NMDS plot (Fig. 3c). Interestingly, the Grand Bay region fell close to the geographically distant Chandeleur Island region within the 2006 NMDS plot, possibly reflecting relatively stable higher salinity regimes.

Mantel tests revealed that correlations between physical distances and Penrose distances in otolith chemistry were non-significant for either year $(2001 \mathrm{r}=-0.107, \mathrm{P}=0.336,1$ tail; $2006 \mathrm{r}=-0.193, \mathrm{P}=0.156$, 1-tail). The correlation between 2001 and 2006 otolith chemistry matrices was also non-significant (2001 vs. $2006 \mathrm{r}=0.370, \mathrm{P}=0.068,1$-tail), and only improved marginally when controlling for the effect of geographical distance (2001 vs. 2006 on geographic residuals: partial $\mathrm{r}=0.400 ; \mathrm{P}=0.056,1$-tail). Thus, geographic proximity did not help much in explaining regional configurations in otolith chemistry. The 2001 regional configuration based on salinity differences correlated strongly with the 2001 regional configuration in otolith chemistry $(\mathrm{r}=$ $0.711, \mathrm{P}=0.00003$, 1-tail). However, the 2006 regional configuration based on salinity differences did not correlate significantly with the 2006 regional configuration in otolith 
(a)

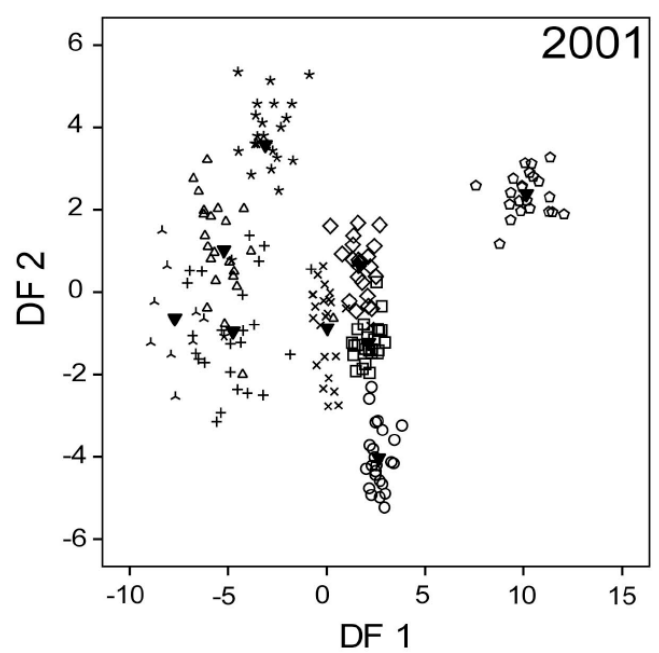

(b)

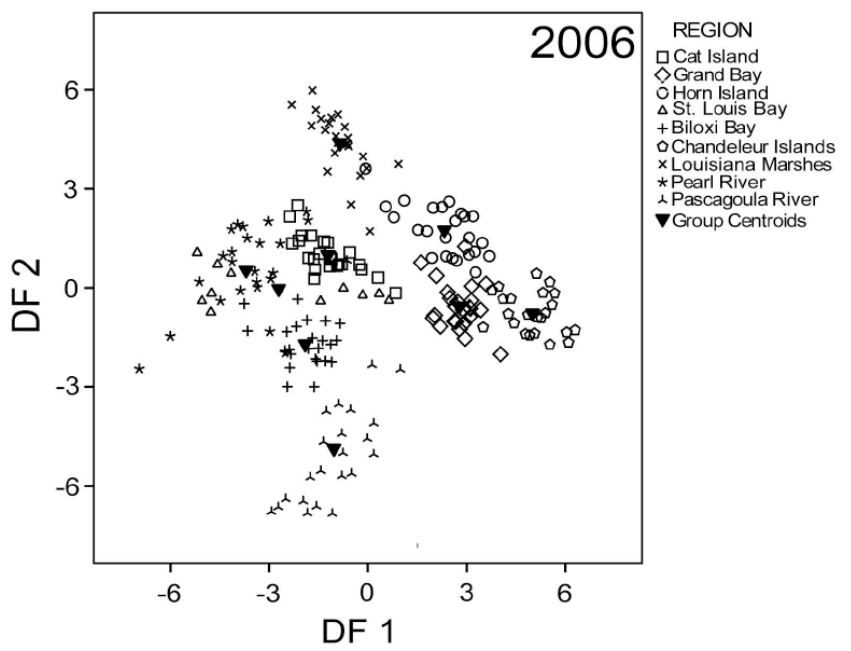

Fig. (2). (a) Plot of DFA coordinates for 197 juvenile Spotted Seatrout collected in 2001 coded into nine regions along the Mississippi coast with group centroids (solid triangles) within the space as defined by the first two canonical discriminant functions. (b) Identical plot for 201 juvenile Spotted Seatrout collected in 2006.

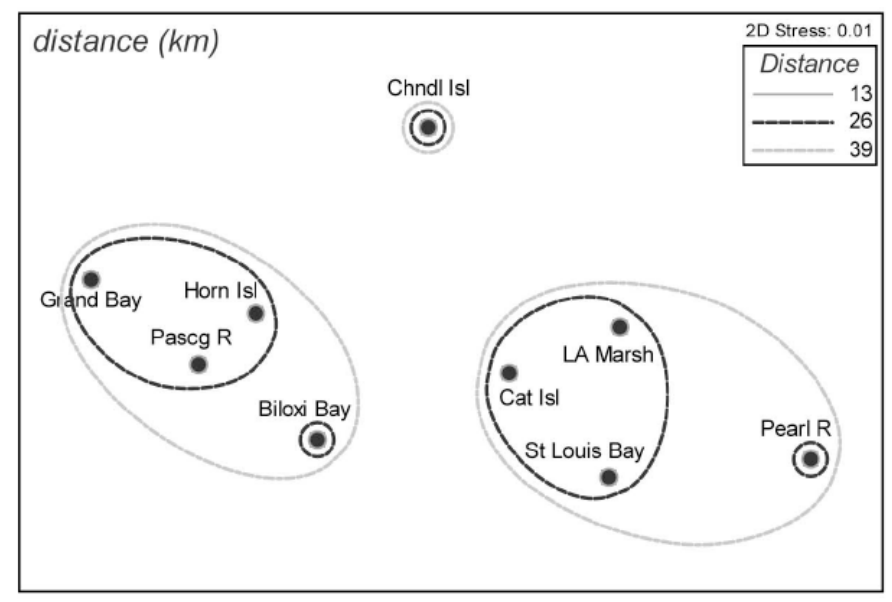

(a)

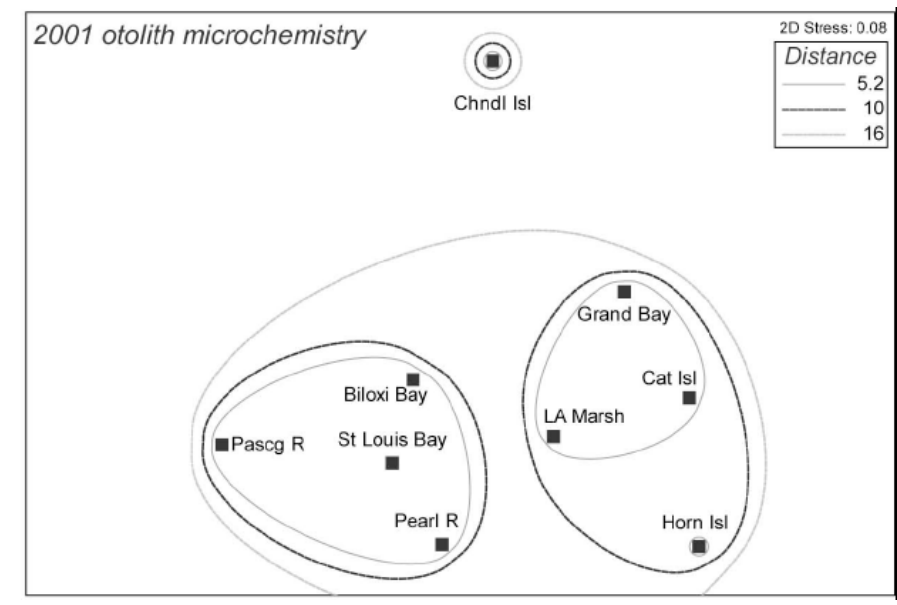

(b)

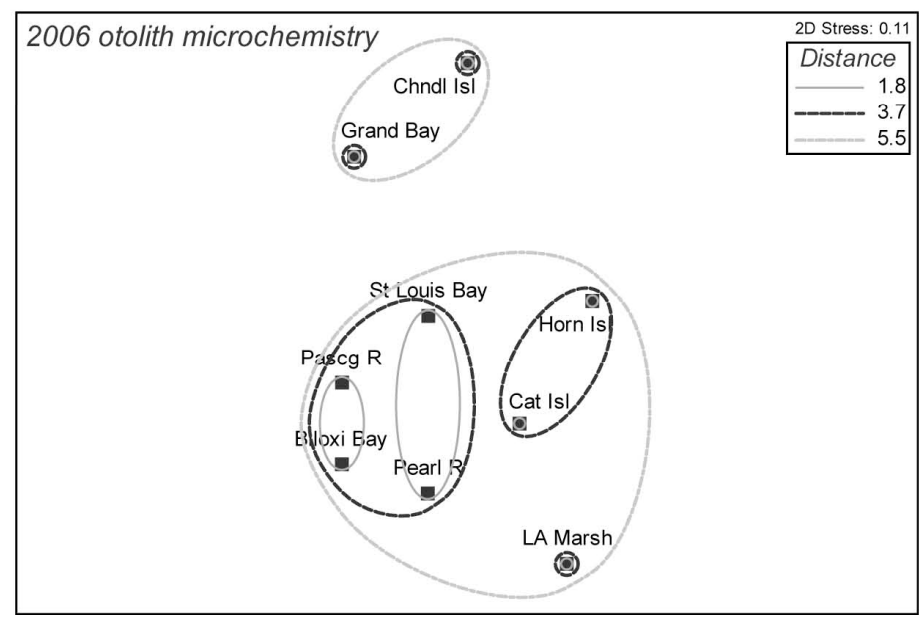

(c)

Fig. (3). NMDS plots derived from Penrose distance matrices representing (a) geographic distances; (b) multivariate distances in DFA space for 2001 otolith data; and (c) multivariate distances in DFA space for 2006 otolith data (Chndl = Chandeleur; Pascg = Pascagoula; LA = Louisiana; $\mathrm{R}=$ River; Isl = Island). 
chemistry $(\mathrm{r}=0.224, \mathrm{P}=0.098,1$-tail), possibly because salinity varied over a much narrower range in 2006. Even so, interregional distances based on salinity were relatively consistent between 2001 and $2006(r=0.761 ; P=0.00005,1$ tail).

As shown by the coincidence of closer proximities and smaller symbol sizes within the 2-D NMDS overlay plot derived from the global DFA, two clusters representing eastern and western regions were relatively similar in otolith chemistry between years (Fig. 4). Conversely, peripherally isolated regions represented by larger symbols within the plot were relatively different in otolith chemistry between years. Such distinctive regions included the Pascagoula River in the east as well as several relatively offshore regions in the west.

\section{Cross-Classification}

The overall proportion of the 2001 fish $(n=197)$ classified correctly based on the 2001 DFA was $93.9 \%$, and regional accuracy varied from 83.3 to $100 \%$. In contrast, the overall proportion of the 2001 fish classified correctly based on the 2006 DFA was only $51.8 \%$, and cross-classification accuracy varied widely among regions (from 0 to $100 \%$ ) (Table 2). Cross-classification accuracy of 2001 fish was high for Grand Bay, Horn Island, the Pearl River, and the Chandeleur Islands. Fish from Biloxi Bay, Cat Island, and St Louis Bay in 2001 were frequently misclassified into nearby regions; whereas 2001 fish from St Louis Bay and the Louisiana Marshes were frequently misclassified into distant regions. Regions from which fish were misclassified were often adjacent to misclassified regions in 2001 NMDS space (Fig. 3b).

The overall proportion of the 2006 fish $(n=201)$ classified correctly based on the 2006 DFA was $94.0 \%$, and regional accuracy varied from 63.6 to $100 \%$. In contrast, the overall proportion of the 2006 fish classified correctly based on the 2001 DFA was only $66.2 \%$ (Table 2). Again, crossclassification accuracy varied widely among regions (from 0 to $100 \%$ ). Cross-classification accuracy of 2006 fish was relatively high for three widely separated regions from which fish were also often correctly classified in the opposing direction, namely Grand Bay, Horn Island, and the Pearl River. Fish from the Pascagoula River, Cat Island, and the Louisiana Marshes in 2006 were frequently misclassified into nearby regions; whereas, 2006 fish from Biloxi Bay and the Chandeleur Islands were frequently misclassified into distant regions. Again, regions into which fish were frequently misclassified were often adjacent to the correct regions in 2006 NMDS space (Fig. 3c).

\section{Otolith Variables}

Classification coefficients from Fisher's linear discriminant functions for the separate-year DFA showed that in $2001, \delta^{18} \mathrm{O}$ ( six), $\delta^{13} \mathrm{C}$ (five), Ba (3), Li (two) and Mn (two), most frequently fell among the top two otolith variables affecting classification functions. In 2006, $\mathrm{Li}$ (seven), $\mathrm{Ba}$ (five), $\delta^{13} \mathrm{C}$ (three), and $\delta^{18} \mathrm{O}$ (three) fell most frequently among the top two otolith variables affecting classification functions. Four otolith variables, including $\delta^{13} \mathrm{C}, \delta^{18} \mathrm{O}, \mathrm{Li}$, and $\mathrm{Ba}$, most often fell among the top two most influential variables affecting cross-classification success.

Most otolith variables within the PCA of the correlation matrix representing the seven otolith variables for 18 yearby-region values (i.e., $\mathrm{n}=18$ ) seemed to follow a hydrological-related pattern, as shown by strong loadings on PCI (Table 3). Three variables, including $\delta^{18} \mathrm{O}, \delta^{13} \mathrm{C}$, and $\mathrm{Li}$, were strongly positively correlated with $\mathrm{PCI}$; and $\mathrm{Sr}$ was strongly inversely correlated with PCI. Moreover, Sr was uncorrelated among regions between years. Thus, the Sr relationship appeared to be hydrological in 2001; whereas, the

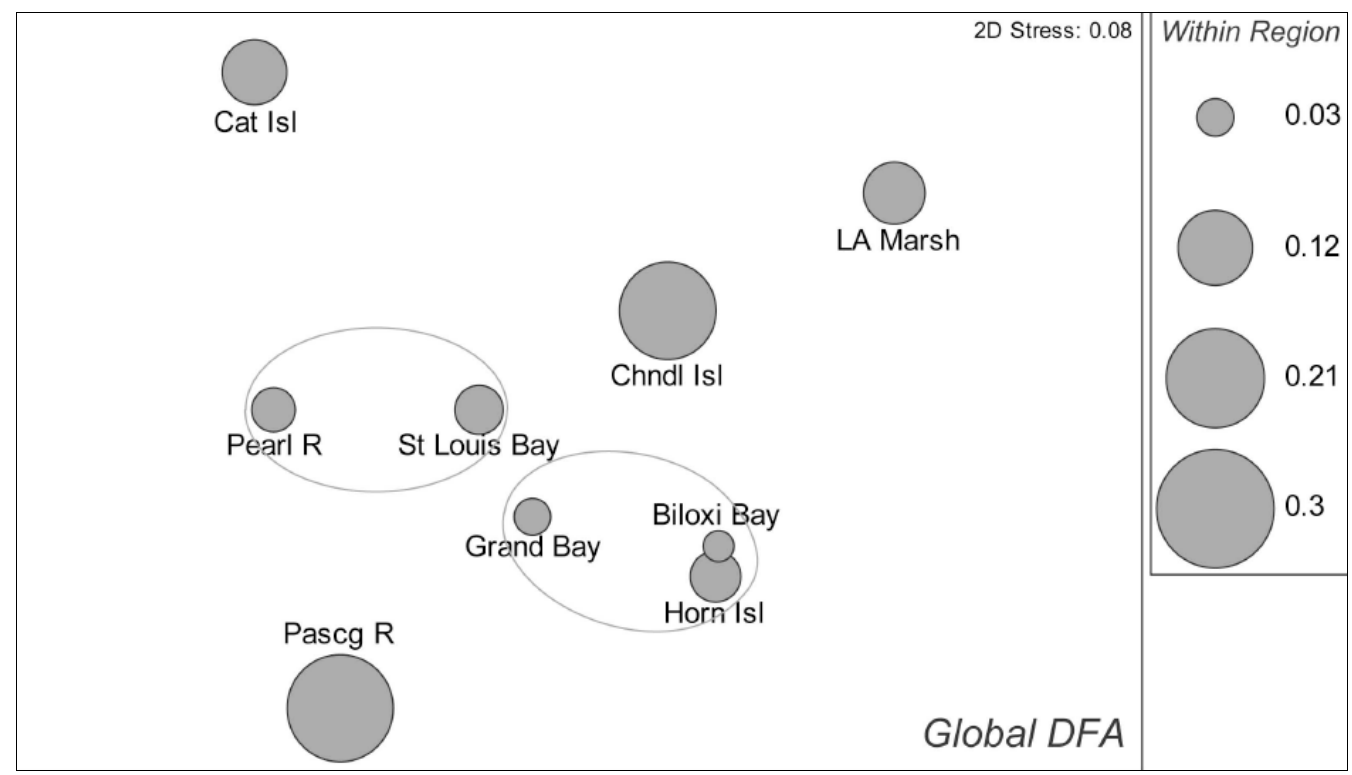

Fig. (4). NMDS overlay plot depicting between-year Penrose distances among regions. Coordinates that are closer are more similar within the global multivariate DFA space representing both years of otolith data. The sizes of the bubbles convey dissimilarity in the regional otolith chemistry (i.e., within region) between years. Ellipses encompass clusters of relatively similar otolith chemistry within western and eastern portions of the study area. $($ Chndl = Chandeleur; Pascg $=$ Pascagoula; LA = Louisiana; $\mathrm{R}=$ River; Isl = Island). 
Table 2. Regional cross-classification summary; Top portion of table shows cross-classification of 2006 Cynoscion nebulosus; bottom portion shows cross-classification of 2001 Cynoscion nebulosus; Diagonals reflect correct classifications; Bottom rows reflect numbers misclassified for each region. $(R=$ River; Isl = Island; Lou. = Louisiana; Miss-Class $=$ misclassified $)$.

\begin{tabular}{|c|c|c|c|c|c|c|c|c|c|c|}
\hline Region & Grand Bay & $\begin{array}{c}\text { Pascagoula } \\
\text { R }\end{array}$ & $\begin{array}{c}\text { Biloxi } \\
\text { Bay }\end{array}$ & Horn Isl & Cat Isl & $\begin{array}{c}\text { Lou. } \\
\text { Marshes }\end{array}$ & $\begin{array}{c}\text { Chandeleur } \\
\text { Isl }\end{array}$ & $\begin{array}{c}\text { St Louis } \\
\text { Bay }\end{array}$ & $\begin{array}{l}\text { Pearl } \\
\text { River }\end{array}$ & Total \\
\hline \multicolumn{11}{|l|}{2006 via 2001} \\
\hline Grand Bay & 24 & --- & --- & --- & --- & --- & --- & --- & --- & 24 \\
\hline Biloxi Bay & --- & --- & 3 & -- & --- & 9 & --- & 11 & 1 & 24 \\
\hline Horn Isl & --- & --- & --- & 18 & 6 & --- & --- & --- & --- & 24 \\
\hline Cat Isl & --- & --- & --- & --- & 2 & 22 & --- & --- & --- & 24 \\
\hline Lou. Marshes & 4 & --- & --- & --- & 19 & $\mathbf{0}$ & 1 & --- & --- & 24 \\
\hline Pearl River & --- & --- & --- & --- & 1 & 5 & --- & --- & 18 & 24 \\
\hline Total Miss Class & 21 & $\mathbf{0}$ & 19 & 1 & 31 & 43 & 1 & 11 & 6 & 68 \\
\hline Region & Grand Bay & $\begin{array}{c}\text { Pascagoula } \\
\text { R }\end{array}$ & $\begin{array}{c}\text { Biloxi } \\
\text { Bay }\end{array}$ & Horn Isl & Cat Isl & $\begin{array}{c}\text { Lou. } \\
\text { Marshes }\end{array}$ & $\begin{array}{c}\text { Chandeleur } \\
\text { Isl }\end{array}$ & $\begin{array}{c}\text { St Louis } \\
\text { Bay }\end{array}$ & $\begin{array}{l}\text { Pearl } \\
\text { River }\end{array}$ & Total \\
\hline \multicolumn{11}{|l|}{2001 via 2006} \\
\hline Grand Bay & 17 & --- & --- & 1 & 3 & 1 & 1 & --- & --- & 23 \\
\hline Pascagoula $\mathbf{R}$ & --- & 6 & 2 & --- & --- & --- & --- & --- & 1 & 9 \\
\hline St Louis Bay & --- & --- & 10 & --- & 1 & --- & --- & $\mathbf{0}$ & 12 & 23 \\
\hline Pearl River & --- & -- & 1 & --- & --- & --- & --- & --- & 23 & 24 \\
\hline Total Miss-Class & $\mathbf{0}$ & 17 & 26 & 25 & 10 & 5 & 4 & $\mathbf{0}$ & 15 & 95 \\
\hline
\end{tabular}

spatial pattern for $\mathrm{Sr}$ appeared to be location-specific under drier conditions in 2006. $\mathrm{Ba}$ and $\mathrm{Mg}$ loaded strongly and positively on PCII, and conveyed location-specific patterns in both years. $\mathrm{Ba}$, which correlated in opposing directions on both PCA factors, was significantly correlated among regions between years. Despite its strong loading on PCII, Mg did not correlate significantly among regions between years. Mn was unique in showing a local regional pattern, in addition to correlating significantly between years. In addition, Mn loaded negatively on both PCI and PCII. Between-year slopes of less than one for significant regressions of 2006 on 2001 regions indicated relatively lower concentrations for $\delta^{18} \mathrm{O}, \delta^{13} \mathrm{C}$, and $\mathrm{Li}$ in 2006 . However, between-year slopes closer to one indicated more similar otolith concentrations for $\mathrm{Mn}$ and $\mathrm{Ba}$ in both years. Interestingly, between-year regressions among regions were not significant for $\mathrm{Mg}$ or $\mathrm{Sr}$; and these two variables were least influential on the regional classification functions.

\section{DISCUSSION}

Using otolith chemistry to understand regional source contributions to stock structure requires detailed knowledge about spatial scales over which natal regions can be reliably discerned [2, 47], as well as the temporal scales over which spatial patterns may vary $[1,29]$. Highly dynamic estuarine ecosystems can both help and hinder the utility of otolith chemistry as a means to characterize stock structure. Spatial 
Table 3. Results of regressions of otolith variables among regions between 2006 and 2001. PCA done with 18 regional values (i.e., 9 regions over two years) for which the first two principal components represented $78 \%$ of the variance in the otolith variables. $\left(P_{(1-t)}-1\right.$-tailed probability associated with between-year $\mathbf{R}^{2}$ values).

\begin{tabular}{|c|c|c|c|c|c|c|}
\hline Otolith Variable & $\mathbf{R}^{2}$ & $\mathbf{P}_{(1-\mathrm{t})}$ & intercept & slope & PCI-Loading & PCII-Loading \\
\hline \hline $\boldsymbol{\delta}^{\boldsymbol{I} \boldsymbol{O}}$ & 0.519 & $<0.0050$ & 0.029 & 0.365 & $\mathbf{0 . 8 9 4}$ & -0.189 \\
\hline $\boldsymbol{\delta}^{13} \boldsymbol{C}$ & 0.848 & $<0.0005$ & 0.018 & 0.556 & $\mathbf{0 . 9 3 6}$ & -0.109 \\
\hline $\mathbf{M n}$ & 0.870 & $<0.0005$ & 0.048 & 0.787 & $\mathbf{- 0 . 5 8 3}$ & $-\mathbf{0 . 5 0 6}$ \\
\hline $\mathbf{B a}$ & 0.617 & $<0.0050$ & 0.044 & 0.892 & 0.016 & $\mathbf{0 . 7 1 4}$ \\
\hline $\mathbf{M g}$ & 0.007 & $>0.2500$ & 0.048 & -0.071 & $\mathbf{0 . 8 8 0}$ \\
\hline $\mathbf{L i}$ & 0.838 & $<0.0005$ & 0.014 & 0.281 & $\mathbf{0 . 9 7 4}$ & -0.064 \\
\hline $\mathbf{S r}$ & 0.021 & $>0.2500$ & 0.006 & -0.084 & $\mathbf{- 0 . 8 4 8}$ & 0.169 \\
\hline
\end{tabular}

scales of resolution amenable to otolith chemistry range over an order of magnitude, from 10 s [18, 48] to 100 s of $\mathrm{km}[31]$. In addition, estuarine fishes often exhibit well-defined spatial and temporal resolution of otolith chemistry [29, 48, 49]. Fine-scale spatial resolution on the order of $25 \mathrm{~km}$ was apparent in both years in the present study, despite disparate hydrological regimes. Comyns et al. [36] previously noted fine scale spatial resolution for the Spotted Seatrout based on the 2001 data. Dorval et al. [35] also found a comparable fine scale of spatial resolution of regional natal areas for juvenile Spotted Seatrout on the US east coast. In the present study, the observed fine-scale of spatial resolution of natal regions likely reflects heterogeneity in water chemistry generated by seven watersheds along the $117 \mathrm{~km}$ coastline of Mississippi.

Natal regions varied widely in the extent of between-year differences in otolith chemistry in the present study. For some regions, otolith chemistry was relatively similar between years, while for other regions otolith chemistry was very different. Consequently, between-year crossclassification success also varied widely among regions. This dichotomy could not be attributed to particular otolith variables, or to any particular geographic pattern. Moreover, there was no commonality among the three regions from which fish were accurately classified in both directions between years. Swearer et al. [6] stressed that otolith elemental fingerprints do vary temporally in connection to the availability of elements within natal source areas in estuarine systems. Although temporal changes in regional classification accuracy based on otolith chemistry are well documented, few studies consider variation in classification accuracy among contiguous regions. However, Patterson et al. 2008 [10] noted that the detection of certain source regions could be obscured by different ambient conditions between years for Red Snapper (Lutjanus campechanus). Such variability in the extent to which fish can be correctly classified into natal regions implies that any given region may vary in its utility for addressing certain questions.

Variation in salinity is one of the most frequently cited environmental correlates in studies of otolith chemistry [11, $13,30,50]$. In the present study, the regions were equally discernible in both years despite uncoupling between salinity and otolith chemistry under the drier regime in 2006. A change in the association between otolith chemistry and salinity in different years was also recently noted for juvenile Spotted Seatrout in Texas [25]. Other hydrological factors in addition to salinity can mediate the availability of trace elements within estuarine systems, including suspended particulate matter (SPM), dissolved organic matter (DOM), $\mathrm{pH}$, and fluvial input [28]. In addition to fluvial sources, various biogeochemical processes can also mediate the availability of ambient elements.

In addition to mediating the availability of elements via their ambient concentrations in response to freshwater discharge and mixing, hydrology may interact with a sundry of physical, biogeochemical, or physiological mechanisms of otolith deposition. For example, the deposition of three influential otolith variables which were interrelated in a way to suggest hydrological influences, $\delta^{18} \mathrm{O}, \delta^{13} \mathrm{C}$, and $\mathrm{Li}$, was likely facilitated by different mechanisms. The otolith stable isotope ratios, $\delta^{18} \mathrm{O}$ and $\delta^{13} \mathrm{C}$, are mediated by different biogeochemical mechanisms relative to freshwater discharge. Although ${ }^{18} \mathrm{O}$ deposits to the otolith matrix directly in proportion to its ambient concentration when at isotopic equilibrium with ${ }^{16} \mathrm{O}$, the equilibrium concentration itself depends on the opposing effects of evaporation and precipitation [9]. The balance between evaporation and precipitation determines rates of depletion vs. enrichment of the light vs. heavy oxygen isotopes, respectively $[51,52]$. In contrast to $\delta^{18} \mathrm{O}$, the availability of $\delta^{13} \mathrm{C}$ is linked to fluvial discharge by way of dissolved inorganic carbon associated with the input of terrestrial carbon. One consequence of this process is that an alternative route for the fractionation of $\mathrm{C}$ isotopes involves physiological mechanisms related to dietary sources of carbon $[51,53]$. Except for a positive relationship with fluvial discharge, little is known about how the otolith deposition of $\mathrm{Li}$ is mediated [43]; but otolith $\mathrm{Li}$ does seem to be more dependent on ambient conditions than on physiology [15].

In this study, both $\mathrm{Sr}$ and $\mathrm{Ba}$ related inversely to discharge, although $\mathrm{Sr}$ usually varies directly with salinity [54, 55]. Comyns et al. 2008 [36] offered several explanations for why Sr might vary inversely with salinity in the Spotted Seatrout, including the use of earlier life-stages and possible species-specific differences in $\mathrm{Sr}$ uptake mechanisms or metabolic pathways. Typically, $\mathrm{Sr}$ serves as a good marker over a broad range of salinity [24]; whereas, the observed 
inverse effect occurred across a narrower salinity gradient in the present study. In terms of interspecific variation, Swearer et al. 2003 [6] noted species-specific differences in salinity relationships for $\mathrm{Sr}$ and $\mathrm{Ba}$ among a suite of estuarine fishes. Moreover, Dorval et al. 2005 [35] noted the lack of a salinity relationship for Sr in Spotted Seatrout on the US East coast. In the present study, the otolith $\mathrm{Sr}$ concentration appeared to be uncoupled from salinity in the drier year.

Although the deposition of divalent cations like $\mathrm{Sr}$ and $\mathrm{Ba}$ within hard parts does reflect their ambient concentrations [6, 48, 56]; trans-membrane physiological mechanisms also mediate how these cations are taken up and substituted for calcium within the otolith matrix [15, 57]. Such confounding of physiology and ambient condition evoked Sturrock et al. 2014 [15] to question the use of $\mathrm{Sr}$ as a marker for tracking fish movements. Perhaps this also explains why $\mathrm{Sr}$ did not exhibit an ontogenetic relationship in the present study, in contrast to other studies that have noted an ontogenetic relationship for this element [15]. Indeed, inconsistency in the use of $\mathrm{Sr}$ as a marker of salinity induced Kerr and Secor 2012 [52] to suggest that $\delta^{18} \mathrm{O}$ may be more dependable for tracking fish movements.

The element $\mathrm{Ba}$ also related inversely to salinity in the present study; and otolith $\mathrm{Ba}$ is regarded as a marker of environmental variability [15]. Unlike $\mathrm{Sr}$, the inverse relationship between $\mathrm{Ba}$ and salinity agrees with the literature [53]. However, the between-year relationship in otolith $\mathrm{Ba}$ concentration among regions also implied location-specific differences in $\mathrm{Ba}$ deposition. Remarkably, the slope of almost one for this relationship indicated much less depletion for $\mathrm{Ba}$ in 2006 compared to other otolith elements. This suggests relative independence from the influence of hydrology on this element. Still, Ba helped to distinguish regional affinities in the present study.

Like for $\mathrm{Ba}$, a slope closer to one for the between-year relationship in otolith concentration among regions indicated less depletion for $\mathrm{Mn}$ in 2006. Furthermore, the betweenyear correlation in $\mathrm{Mn}$ concentration suggested a regionallocal pattern (i.e., proximate coordinates represent regions that are geographically closer). This spatial pattern might reflect biogeochemical controls on this redox sensitive element, which involves the benthic flux of its particulate phase in estuaries [30]. Alternatively, it is also known that diet contributes to organismal Mn levels [15].

In the present study, the divalent element, $\mathrm{Mg}$, exhibited a unique pattern in that it was neither significantly related among regions between years nor was it strongly related to hydrology. Martin and Thorrold 2005 [58] observed that the relationship of otolith $\mathrm{Mg}$ to water concentration was not well established. Furthermore, Patterson et al. 2008 [10] found that otolith $\mathrm{Mg}$ was not related to any physical factors, including salinity or temperature, for juvenile Red Snapper in the northern GoM. They further noted that Elsdon and Gillanders 2002 [59] found that otolith $\mathrm{Mg}$ correlated with somatic growth, which likely signaled greater metabolic demands for $\mathrm{Mg}$ in conjunction with higher growth rates [15].

In conclusion, it would be misleading to apply an effective DFA using an arbitrary suite of variables from one year to discriminate natal source regions in other years for the important estuarine resident, Spotted Seatrout. To effectively distinguish fish in the present study, it was necessary to develop separate DFAs for each year. Patterson et al. 2008 [10] concluded that otolith chemistry fingerprints reflect a complex web of mechanisms. The present study further reinforces that conclusion for Spotted Seatrout. Moreover, in addition to elucidating limitations of using otolith chemistry to identify natal source regions or for tracking fish movements, knowing more about how and why otolith chemistry varies might be useful for addressing specific questions about early recruitment dynamics, or to aid in the development of more reliable instruments for discerning natal source contributions. In light of findings like ours, it may be feasible to tailor studies to address questions that just involve regions exhibiting consistent otolith chemistry or that only use otolith variables with appropriate attributes.

\section{CONFLICT OF INTEREST}

The authors confirm that this article content has no conflict of interest.

\section{ACKNOWLEDGEMENTS}

A number of graduate students participated in field sampling, including P. Grammer, G. Grammer, G. Zapfe, N. Cotton, S. Griffith and C. Woodley. Special thanks go to P. Grammer who did much of the field and lab work for this study. D. Winter of the University of California at Davis provided invaluable assistance in analyzing otoliths for isotope ratios. L. Gross and J. Shiller of the University of Southern Mississippi, Department of Marine Science, assisted with the trace element analyses. G. Grammer provided logistical help with sampling within the Grand Bay Estuarine Research Reserve. Finally, we appreciate the constructive comments and suggestions of anonymous reviewers who contributed to this paper. This research was sponsored by the US Department of Commerce, National Oceanic and Atmospheric Administration, through the Mississippi-Alabama Sea Grant Consortium (MASGC) (grants R:SP-4 and R/CEH14). The US Government and the MASGC are authorized to produce and distribute reprints notwithstanding any copyright notation that may appear hereon. The views expressed herein are those of the authors and do not necessarily reflect the views of NOAA or any of its sub-agencies.

\section{REFERENCES}

[1] Hamer PA, Jenkins GP, Gillanders BM. Otolith chemistry of juvenile Snapper Pargus auratus in Victorian waters: natural chemical tags and their temporal variation. Mar Ecol Prog Ser 2003; 263: 261-73.

[2] Elsdon TS, Wells BK, Campana SE, et al. Otolith chemistry to describe movements and life-history parameters of fishes: hypotheses, assumptions, limitations and inferences. Oceanogr Mar Biol 2008; 46: 297-330.

[3] Campana SE, Gagné JA. Cod stock discrimination using ICPMS elemental assays of otoliths. In: Secor DH, Dean JM, Campana SE, Eds. Recent developments in fish otolith research; University of South Carolina Press, Columbia: SC 1995; pp. 671-91.

[4] Thorrold SR, Jones CM, Swart PK, Targett TE. Accurate classification of juvenile Weakfish Cynoscion regalis to estuarine nursery areas based on chemical signatures in otoliths. Mar Ecol Prog Ser 1998; 173: 253-65.

[5] Thresher, R.E. Elemental composition of otoliths as a stock delineator in fishes. Fish Res 1999; 43: 165-204. 
[6] Swearer SE, Forrester GE, Steele MA, Brooks AJ, Lea DW. Spatio-temporal and interspecific variation in otolith trace-elemental fingerprints in a temperate estuarine fish assemblage. Estuar Coast Shelf S 2003; 56: 1111-23.

[7] Gibb FM, Gibb IM, Wright PJ. Isolation of Atlantic Cod (Gadus morhua) nursery areas. Mar Biol 2007; 151: 1185-94.

[8] Gahagan BI, Vokoun JC, Whitledge GW, Schultz ET. Evaluation of otolith microchemistry for identifying natal origin of anadromous River Herring in Connecticut. Mar Coast Fish Dynam Manag Ecosys Sci 2012; 4: 358-72.

[9] Campana SE. Chemistry and composition of fish otoliths: pathways, mechanisms and applications. Mar Ecol Prog Ser 1999; 188: 263-97.

[10] Patterson WF III, Cowan JH Jr., Wilson CA, Chen Z. Temporal and spatial variability in juvenile Red Snapper otolith elemental signatures in the northern Gulf of Mexico. T Am Fish Soc 2008; 137: $521-32$

[11] Dorval E, Jones CM, Hannigan R, van Montfrons J. Relating otolith chemistry to surface water chemistry in a coastal plain estuary. Can J Fish Aquat Sci 2007; 64: 411-24.

[12] Tanner SE, Reis-Santos P, Vasconcelos RP, França S, Thorrold SR, Cabral HN. Otolith geochemistry discriminates among estuarine nursery areas of Solea solea and S. senegalensis over time. Mar Ecol Prog Ser 2012; 452: 193-203.

[13] Tanner SE, Reis-Santos P, Vasconcelos RP, et al. Does otolith geochemistry record ambient environmental conditions in a temperate tidal estuary? J Exp Mar Biol Ecol 2013; 441: 7-15.

[14] Bath GE, Thorrold SR, Jones CM, Campana SE, McLaren JW, Lam JWH. Strontium and barium uptake in aragonitic otoliths of marine fish. Geochim Cosmochim Acta 2000; 64: 1705-14.

[15] Sturrock AM, Trueman CN, Milton JA, Waring CP, Cooper MJ, Hunter E. Physiological influences can outweigh environmental signals in otolith microchemistry research. Mar Ecol Prog Ser 2014; 500: 245-64.

[16] Walther BD, Kingsford MJ, O'Callaghan MD, McCulloch MT. Interactive effects of ontogeny, food ration and temperature on elemental incorporation in otoliths of a coral reef fish. Env Biol Fish 2010; 89: 441-51.

[17] Gillanders BM, Kingsford MJ. Elemental fingerprints of otoliths of fish may distinguish estuarine 'nursery' habitats. Mar Ecol Prog Ser 2000; 201: 273-86.

[18] Clarke LM, Walther BD, Munch SB, Thorrold SR, Conover DO. Chemical signatures in the otoliths of a coastal marine fish, Menidia menidia, from the northeastern United States: spatial and temporal differences. Mar Ecol Prog Ser 2009; 384: 261-71.

[19] Warner RR, Swearer SE, Caselle JE, Sheehy M, Paradis G. Natal trace-elemental signatures in the otoliths of an open-coast fish. Limnol Oceanogr 2005; 50: 1529-42.

[20] Cook GS. Changes in otolith microchemistry over a protracted spawning season influence assignment of natal origin. Mar Ecol Prog Ser 2011; 423: 197-209.

[21] Elsdon TS, Gillanders BM. Fish otolith chemistry influenced by exposure to multiple environmental variables. J Exp Mar Biol Ecol 2004; 313: 269-84.

[22] Hamer PA, Jenkins GP. Comparison of spatial variation in otolith chemistry of two fish species and relationships with water chemistry and otolith growth. J Fish Biol 2007; 71: 1035-55.

[23] Pangle KL, Ludsin SA, Fryer BJ. Otolith microchemistry as a stock identification tool for freshwater fishes: testing its limits in Lake Erie. Can J Fish Aquat Sci 2010; 67: 1475-89.

[24] Macdonald JI, Crook DA. Variability in Sr:Ca and Ba:Ca ratios in water and fish otoliths across an estuarine salinity gradient. Mar Ecol Prog Ser 2010; 413: 147-61.

[25] Curtis, M, Stunz GW, Overath RD, Vega RR. Otolith chemistry can discriminate signatures of hatchery-reared and wild Spotted Seatrout. Fish Res 2014; 153: 31-40.

[26] Rondeau B, Cossa D, Gagnon P, Pham TT, Surette C. Hydrological and biogeochemical dynamics of the minor and trace elements in the St. Lawrence River. Appl Geochem 2005; 20: 1391-408.

[27] Schaffler JJ, Winkelman DL. Temporal and spatial variability in otolith trace-element signatures of juvenile Striped Bass from spawning locations in Lake Texoma, Oklahoma-Texas. T Am Fish Soc 2008; 137: 818-29.

[28] Shiller AM. Dissolved trace elements in the Mississippi River: Seasonal, interannual, and decadal variability. Geochim Cosmochim Acta 1997; 61: 4321-30.
[29] Gillanders BM. Using elemental chemistry of fish otoliths to determine connectivity between estuarine and coastal habitats. Estuar Coast Shelf S 2005; 64: 47-57.

[30] Leakey CDB, Attrill MJ, Fitzsimons MF. Multi-element otolith chemistry of juvenile Sole (Solea solea), Whiting (Merlangius merlangus) and European Seabass (Dicentrarchus labrax) in the Thames Estuary and adjacent coastal regions. J Sea Res 2009; 61: 268-74.

[31] Patterson HM, McBride RS, Julien N. Population structure of Red Drum (Sciaenops ocellatus) as determined by otolith chemistry. Mar Biol 2004; 144: 855-62.

[32] Johnson DR, Seaman W Jr. Species profiles: life histories and environmental requirements of coastal fishes and invertebrates (south Florida) - Spotted Seatrout. Biol Rep US Fish Wildl Serv 1986; 82: 18 .

[33] Fulford RS, Hendon JR. Evaluating management actions for Spotted Seatrout, Cynoscion nebulosus, in Mississippi with an agestructured projection model. Gulf Caribb Res 2010; 22: 51-61.

[34] McMichael RH Jr., Peters KM. Early life history of Spotted Seatrout, Cynoscion nebulosus (Pisces: Sciaenidae), in Tampa Bay, Florida. Estuaries 1989; 12: 98-110.

[35] Dorval E, Jones CM, Hannigan R, van Montfrans J. Can otolith chemistry be used for identifying essential seagrass habitats for juvenile Spotted Seatrout, Cynoscion nebulosus, in Chesapeake Bay? Mar Freshwater Res 2005; 56: 645-53.

[36] Comyns BH, Rakocinski CF, Peterson MS, Shiller A. Otolith chemistry of juvenile Spotted Seatrout (Cynoscion nebulosus) reflects local natal regions of coastal Mississippi. Mar Ecol Prog Ser 2008; 371: 243-52.

[37] Dorval E, Jones CM, Hannigan R. Chemistry in surface waters: distinguishing fine scale differences in seagrass habitats of Chesapeake Bay. Limnol Oceanogr 2005; 50: 1073-83.

[38] Pillar VD, Orlóci L. On randomization testing in vegetation science: multifactor comparisons of relevé groups. J Veg Sci 1996; 7: 585-92.

[39] Pillar VD. MULTIV - Multivariate Exploratory Analysis, Randomization Testing and Bootstrap Resampling. User's Guide v. 2.4. Porto Alegre, Brazil: Universidade Federal do Rio Grande do Sul 2006; p. 51.

[40] Edmonds JS, Fletcher WJ. Stock discrimination of Pilchards Sardinops sagax by stable isotope ratio analysis of otolith carbonate. Mar Ecol Prog Ser 1997; 152: 241-7.

[41] Begg GA,Weidman CR. Stable $\delta^{13} \mathrm{C}$ and $\delta^{18} \mathrm{O}$ isotopes in otoliths of Haddock Melanogrammus aeglefinus from the northwest Atlantic Ocean. Mar Ecol Prog Ser 2001; 216: 223-33.

[42] Høie H, Folkvord A, Otterlei E. Effect of somatic and otolith growth rate on stable isotopic composition of early juvenile Cod (Gadus morhua L) otoliths. J Exp Mar Biol Ecol 2003; 289: 41-58.

[43] Brown JA. Classification of juvenile flatfishes to estuarine and coastal habitats based on the elemental composition of otoliths. Estuar Coast Shelf S 2006; 66: 594-611.

[44] Burns RP, Burns R. Business Research Methods and Statistics using SPSS. London: SAGE Publications Ltd 2008; p. 560.

[45] Kolowski M, Nielsen CK. Using Penrose distance to identify potential risk of wildlife-vehicle collisions. Biol Cons 2008; 141: 1119-28.

[46] Bonnet E, Van de Peer Y. ZT: a software tool for simple and partial Mantel tests. J Stat Softw 2002; 7: 1-12.

[47] Gillanders BM. Connectivity between juvenile and adult fish populations: do adults remain near their recruitment estuaries? Mar Ecol Prog Ser 2002; 240: 215-23.

[48] Lara MR, Jones DL, Chen Z, Lamkin JT, Jones CM. Spatial variation of otolith elemental signatures among juvenile Gray Snapper (Lutjanus griseus) inhabiting southern Florida Waters. Mar Biol 2008; 153: 235-48.

[49] Tanner SE, Vasconcelos RP, Reis-Santos P, Cabral HN, Thorrold SR. Spatial and ontogenetic variability in the chemical composition of juvenile Common Sole (Solea solea) otoliths. Estuar Coast Shelf S 2011; 91: 150-7.

[50] Nishimoto MN, Washburn L, Warner RR, Love MS, Paradis GL. Otolith elemental signatures reflect residency in coastal water masses. Environ Biol Fishes 2010; 89: 341-56.

[51] Rooker JR, Stunz GW, Holt SA, Minello TJ. Population connectivity of Red Drum in the northern Gulf of Mexico. Mar Ecol Prog Ser 2010; 407: 187-96. 
[52] Kerr LA, Secor DH. Partial migration across populations of White Perch (Morone americana): a flexible life history strategy in a variable estuarine environment. Estuar Coast 2012; 35: 227-36.

[53] Thorrold SR, Jones CM, Campana SE. Response of otolith microchemistry to environmental variations experienced by larval and juvenile Atlantic Croaker (Micropogonias undulatus). Limnol Oceanogr 1997; 42: 102-11.

[54] Kalish JM. Use of otolith microchemistry to distinguish the progeny of sympatric anadromous and non-anadromous salmonids. Fish Bull 1990; 88: 657-66.

[55] Secor DH, Rooker JR. Is otolith strontium a useful scalar of life cycles in estuarine fishes? Fish Res 2000; 46: 359-71.
[56] Campana SE, Thorrold SR. Otoliths, increments, and elements: keys to a comprehensive understanding of fish populations? Can J Fish Aquat Sci 2001; 58: 30-8.

[57] Kalish JM. Determinants of otolith chemistry: seasonal variation in the composition of blood plasma, endolymph and otoliths of Bearded Rock Cod Pseudophycis barbatus. Mar Ecol Prog Ser 1991; 74: 137-59.

[58] Martin GB, Thorrold SR. Temperature and salinity effects on magnesium, manganese, and barium incorporation in otoliths of larval and early juvenile Spot Leiostomus xanthurus. Mar Ecol Prog Ser 2005; 293: 223-32.

[59] Elsdon TS, Gillanders BM. Interactive effects of temperature and salinity on otolith chemistry: Challenges for determining environmental histories of fish. Can J Fish Aquat Sci 2002; 59: 1796-808.

(C) Rakocinski et al.; Licensee Bentham Open.

This is an open access article licensed under the terms of the Creative Commons Attribution Non-Commercial License (http://creativecommons.org/licenses/by-nc/3.0/) which permits unrestricted, non-commercial use, distribution and reproduction in any medium, provided the work is properly cited. 